NASA Contractor Report 191153

AlAA-93-2555

NASA-CR-191153

19930019420

Navier-Stokes Analysis of Radial Turbine Rotor Performance

L.M. Larosiliere

Ohio Aerospace Institute

Brook Park, Ohio

Prepared for the

29th Joint Propulsion Conference and Exhibit cosponsored by the AIAA, SAE, ASME, and ASEE

Monterey, California, June 28-30, 1993

AUG $\mid 1993$ 


\title{
NAVIER-STOKES ANALYSIS OF RADIAL TURBINE ROTOR PERFORMANCE
}

\author{
L.M. Larosiliere \\ Ohio Aerospace Institute \\ 22800 Cedar Point Road \\ Brook Park, Ohio 44142
}

\begin{abstract}
An analysis of flow through a radial turbine rotor using the three-dimensional, thinlayer Navier-Stokes code RVC3D is described. The rotor is a solid version of an air-cooled metallic radial turbine having thick trailing edges, shroud clearance, and scalloped-backface clearance. Results are presented at the nominal operating condition using both a zero-clearance model and a model simulating the effects of the shroud and scalloped-backface clearance flows. A comparison with the available test data is made and details of the internal flow physics are discussed, allowing a better understanding of the complex flow distribution within the rotor.
\end{abstract}

\section{INTRODUCTION}

Gas turbine cycle studies have shown that higher specific power and improved specific fuel consumption can be achieved through increases in both turbine inlet temperature and cycle pressure ratio. This implies a significant reduction in corrected mass flow rates resulting in reduced throughflow passage heights. Relative to axial stages, radial turbines have demonstrated lower sensitivity to the efficiency penalties of reduced passage heights and hence, become very competitive at low corrected flow rates.

Exploitation of the performance advantages of the radial turbine at low corrected mass flow rates resulting from higher temperature and cycle pressure ratio requires the development of high temperature capabilities in such turines. This development effort is currently being pursued through advanced materials research. However, the design and fabrication of an air-cooled metallic radial turbine for rotorcraft engines with high power-to-weight and improved specific fuel consumption requirements have been reported by Snyder and Roelke [1].

Detailed aerodynamic testing including "on-rotor" static pressure measurements has been performed at NASA Lewis Research Center on a solid version of the air-cooled metallic radial turine. This solid rotor, fabricated without coolant passages, is identical in every other respect with the cooled rotor. Some performance data from this experimental evaluation was reported by Tirres [2]. In an effort to understand the flow structure within the rotor and to complement the experimental data, a three-dimensional computational fluid dynamic evaluation of the performance of the solid rotor was undertaken.

The use of three-dimensional computational fluid dynamics is becoming commonplace in the turbomachinery community. Zangeneh-Kazemi et al. [3] have analyzed the flow in a radial turbine rotor and reported good agreement with measured shroud static pressures and exit flow distribution. Heidmann and Beach [4] applied a three-dimensional viscous code to gain insight into the flow physics of a radial turbine rotor. Reasonable agreement with measured exit circumferentially-averaged radial profiles and shroud static pressures were reported. Heidman [5] later applied Adamczyk's "average passage" code [6] to analyze the flow in a radial turbine stage which had the same rotor as in reference 4 . Slightly better agreement with the measured exit profiles was obtained when the effects of the upstream nozzle were accounted for.

The above studies emphasized the accurate description of flow distribution within the rotor. Recently Chima [7] has applied a thin-layer Navier-Stokes approach to predict the design speed performance characteristics of a transonic compressor rotor. The overall design point 
performance (i.e., efficiency, and work) was well matched and also, a good representation of the circumferentially-averaged spanwise profiles was obtained. Chima's code uses a boundary-fitted periodic $\mathrm{C}$-mesh allowing a smooth discretization of blade profile leading and trailing edges. This type of meshing also provides better surface and wake-path resolution than $\mathrm{H}$-meshes employed in references [3-5]. The solid version of the cooled rotor considered herein has thick trailing and leading edges thereby making the C-mesh important if a good quantitative prediction of performance as well as a reliable description of flow distribution are to be expected.

In the present study, the threedimensional, thin-layer Navier-Stokes code of Chima was employed to evaluate the aerodynamic performance of the solid version of the cooled radial-turbine rotor. The code was adapted to the radial turbine geometry and a simple shroud and backface clearance flowmodel was included. Results are presented at the nominal operating condition using both a "zeroclearance" model and a model simulating the effects of the shroud and scalloped-backface clearance flows. A comparison between the computed results and the measured data is made. This provides some support for the validity of the computation as a representation of the rotor intemal flow structure. Details of the internal flow physics are discussed, allowing a better understanding of the complex flow distribution within the rotor.

\section{ROTOR GEOMETRY AND SUPPORTING EXPERIMENTAL DATA}

The main dimensions of the rotor are shown in Figure 1. These dimensions reflect the 1.8 times scaled-up rotor required to match the NASA Lewis experimental rig. Details of the blading design can be found in reference 1 . This rotor consists of 13 radial filament blades, commonly used in radial turbines to eliminate bending stresses caused by rotational forces. A nozzle ring, consisting of 15 vanes with a five inch chord which tum the flow approximately 74 degrees from the radial direction, is situated upstream of the rotor. Rotor geometric parameters are given in Table I. The edge thicknesses are given as a percentage of staggered spacing $s \cos (\beta)$, where $s$ is the circumferential pitch and $\beta$ is the local blade angle. Note the large thickness blockage at the hub trailing-edge and also the large backface clearance in addition to the familiar shroud clearance. This backface clearance is a result of scalloping of the rotor in order to reduce weight and minimize centrifugal disk stresses. Scalloping causes the rotor disk surface not to extend completely to the rotor leading edge. Instead, the flow is bounded by the stationary backface in this region.

Details of the experimental-setup for the aerodynamic testing of the rotor can be found in reference 2 . The rotor mass flow rate was determined using a venturi flow meter. Radial surveys of total pressure, total temperature, and flow angle were made $0.853 \mathrm{~cm}$ upstream of the rotor leading edge (STA (2), Fig. 1) and $6.735 \mathrm{~cm}$ downstream (STA (3), Fig. 1) of the rotor trailing edge using conventional probes. Twenty-eight "on-rotor" static pressure taps were distributed on the pressure and suction sides of the blade at approximate meridional streamline locations of 22 percent and 71 percent span. Static pressure taps were also located along the periphery of the hub at the rotor exit. Table II presents the nominal operating conditions of the rotor. The rotor inlet values shown were obtained by shifting the near leading-edge traverse data to the computational grid inlet. This shifting was done in an average fashion while conserving mass, energy, and angular momentum. Since the measured flow angle at the rotor-inlet traverse plane was relatively constant over most of the span, a constant angle was assumed. The endwall boundary layer thicknesses were estimated from the total-pressure traverse data. Exit traverse data and "on-rotor" static pressure measurements were acquired at this nominal operating condition. The bulk of this data has not been published yet and only fragments of it are used for validation of the computational results presented herein. 
TABLE I.-TURBINE ROTOR BLADING PARAMETERS

\begin{tabular}{||l|l|}
\hline Rotor inlet radius, $\mathrm{cm}$ & 18.287 \\
\hline Ratio of rotor exit tip to inlet radii & 0.650 \\
\hline Ratio of rotor exit hub to inlet radii & 0.335 \\
\hline Number of rotor blades & 13 \\
\hline \begin{tabular}{||c|} 
Rotor leading-edge thickness, percent of staggered spacing \\
Hub \\
Shroud
\end{tabular} & 11.1 \\
\hline Rotor trailing-edge thickness, percent of staggered spacing \\
Hub \\
Shroud & 6.3 \\
\hline Rotor-Shroud clearance, percent of span & 38.5 \\
Inlet (axial) & 10.04 \\
\hline Exit (radial) & \\
\hline Rotor-backface clearance, percent of span & 5.8 \\
\hline
\end{tabular}

Table II.- TURBINE ROTOR OPERATING CONDITIONS

\begin{tabular}{||l|l||}
\hline Mass-averaged inlet total temperature, degrees Kelvin & 478.09 \\
\hline Mass-averaged inlet total pressure, $\mathrm{N} / \mathrm{m}^{2}$ & $1.99 \times 10^{5}$ \\
\hline Inlet absolute flow angle, degrees from radial & 74.15 \\
\hline Rotative speed, RPM & 19487 \\
\hline Exit static pressure at hub, $\mathrm{N} / \mathrm{m}^{2}$ & $4.85 \times 10^{4}$ \\
\hline Inlet casing boundary layer thickness, percent span & 9.0 \\
\hline Inlet hub boundary layer thickness, percent span & 18.0 \\
\hline
\end{tabular}

\section{DESCRIPTION OF ANALYSIS}

The computer code RVC3D developed by Chima [7] was adapted to the radial turbine configuration. A model of the flow field is formulated in terms of the Reynolds' averaged Navier-Stokes equations in the blade-relative frame using Cartesian coordinates. These equations are then mapped to a general bodyfitted coordinate system. The thin-layer approximation [8] is invoked in order to neglect all viscous derivatives in the streamwise direction while retaining those in the other coordinate directions. The system is closed by the perfect gas equation of state and a three-dimensional adaptation of the two-layer mixing length turbulence model of Baldwin and Lomax [8].

Chima [7], and Chima and Yokota [9] give details of the numerical implementation of the three-dimensional, thin-layer Navier-Stokes analysis. Briefly, the code uses finite difference discretization on a periodic $\mathrm{C}$-mesh and a fourstage explicit Runge-Kutta time marching algorithm. Numerical dissipation is added to gain solution stability but is reduced in viscous 
dominated flow regions. Local time stepping and implicit residual smoothing with a CFL number of 5 were used to increase the rate of convergence.

For the inflow boundary condition, total temperature, total pressure, and the absolute flow angle were specified. The upstream-running Riemann invariant was extrapolated from the interior thereby allowing all other inflow variables to be determined. Inlet total pressure was specified as a constant in the core flow and reduced in the endwall regions according to a turbulent law-of-the wall velocity profile, with the inlet boundary layer thicknesses given in Table II. The inlet total temperature and absolute flow angle were specified as constants (Table II). At the outflow boundary, the measured hub static pressure was specified and simple radialequilibrium was employed to obtain the static pressure at other locations. All other outflow variables were extrapolated from within.

No-slip boundary conditions were enforced at the hub and shroud endwalls of the rotor flowpath and along the blade surface. In addition, adiabatic walls were specified. Surface conditions were obtained by solving the component of the momentum equation normal to the wall. Periodicity was enforced along the outer boundaries of the $\mathrm{C}$-mesh in the circumferential direction.

The computational mesh was generated with the code TCGRID developed at NASA Lewis by Chima [7]. A C-mesh consisting of 200 quasiorthogonals, 50 quasi-streamlines, and 50 bladeto-blade stations was employed. This mesh is illustrated in Figure 2 highlighting the rotor leading and trailing edge resolutions. The inflow boundary is at a radius of $19.506 \mathrm{~cm}$, very close to the rotor leading edge $(R=18.287 \mathrm{~cm})$. The outflow boundary is located at the exit survey plane used in the experimental evaluation. The mesh was refined near the blade surfaces and endwalls using hyperbolic tangent clustering. This clustering results in the nearest mesh node to the endwalls and blade surfaces being on the order of $y^{+}=2.0$ as recommended by Boyle [10].

The computations were performed with a stationary shroud, implying relative motion between blades and the shroud. Two sets of computations were performed, one with and the other without modelling the backface and shroud clearance flows. For the case with backface clearance, the backface in the clearance region was specified to be stationary. In the clearance regions, the flow variables at the projected surface of the blade were made periodic at constant arc-length. This induces fluid to flow from the high pressure region adjacent to the pressure surface into the low pressure region adjacent to the suction surface. The computational shroud clearance varies from 1.94 percent of span at the leading edge to 1.1 percent of span at the trailing edge. The computational backface clearance is relatively constant at 7.3 percent of span from leading edge to the end of the clearance ( $R=12.710$ $\mathrm{cm})$. These values of computational clearances were chosen in order to account for the vena contracta as described in a model proposed by Rains [11] and recently applied in a CFD code by Kitley et al. [12].

A CPU time of approximately 3 seconds per iteration was required on a Cray YMP computer. Typically, the solution converged within 3000 iterations, including start-up from an initial guess consisting of the inlet conditions. The startup phase demanded a careful monitoring of convergence criteria and skilful application of damping parameters. About 9MW of core were required for the 500,000 grid points employed.

\section{EXPERIMENTAL SUPPORT FOR COMPUTATIONAL ANALYSIS}

\section{Overall Performance}

Overall performance of the rotor at the nominal conditions given in Table II was obtained for the two flow models considered herein. The computational results were averaged blade-toblade using a momentum-averaging procedure that corresponds to approximately a "mixed-out" average. The radial distributions were massaveraged spanwise to produce the overall averages. To arrive at the experimental rotor overall performance, the rotor inlet traverse data was employed to estimate the stator efficiency decrement from the measured overall adiabatic efficiency. A five percent stator total pressure loss was estimated based on the traverse data and a 
TABLE III.-COMPARISONS OF OVERALL PERFORMANCE

\begin{tabular}{||l|l|l|l|l||}
\hline & $\begin{array}{l}\text { mass flow } \\
(\mathrm{kg} / \mathrm{s})\end{array}$ & $\begin{array}{l}\text { adia. eff. } \\
\text { (tot-tot) }\end{array}$ & $\begin{array}{l}\text { press. rat. } \\
\text { (tot-tot) }\end{array}$ & $\begin{array}{l}\text { temp. rat. } \\
\text { (tot-tot) }\end{array}$ \\
\hline zero clearance & 1.848 & 0.918 & 0.264 & 0.714 \\
\hline measured data & 1.837 & 0.890 & 0.260 & 0.720 \\
\hline backface \& shroud clear. & 1.840 & 0.891 & 0.263 & 0.722 \\
\hline
\end{tabular}

data match of the overall performance using the mean-line performance evaluation code RTOD developed by Meitner and Glassman [13]. Comparisons of the computed rotor overall performance with the measured data are shown in Table III. It can be observed that the inclusion of the backface and shroud leakage model results in a very good match with the measured data.

\section{Rotor Exit Survey}

A rotor exit (STA. 3) radial survey was taken at one circumferential position for the nominal operating point. Figure 3 shows a comparison of this data with the circumferentiallyaveraged spanwise profiles computed at the rotor exit. The spanwise distribution of absolute flow angle $\left(\alpha=\arctan \left(v_{\theta} / u\right)\right)$ is shown in Fig. 3 (a) for the zero clearance flow-model, the measured data, and the backface and shroud clearance flow-model. Negative flow angles indicate a tangential component of absolute velocity opposite to the direction of rotor rotation. The computed flow angles correlate adequately with the measured data especially for the backface and shroud clearance model near the lower portion of the span. A maximum of 3 degrees difference exists between the data and the computations. This is probably within the accuracy level of the measurement system. Good agreement with the measured data can be observed for the spanwise total pressure distribution ( Fig. 3 (b) ) and the corresponding total temperature distribution ( Fig. 3 (c) ). These figures show that the spanwise profiles downstream of the rotor are affected very little by the clearances except at the hub where the case with clearance has a higher total pressure than the zero clearance case. This may be due to the occurrence of extreme spanwise mixing from the rotor trailing edge to the rotor exit. Also, note that the computed spanwise profiles of exit swirl angle are merely shifted downward over most of the span with the inclusion of clearance. This may be an indication that the effect of the present clearance flow-model is mostly one of flow blockage downstream of the trailing edge. Further insights into this blockage effect are given later in the discussion of the internal flow structure.

Rotor Surface Static Pressure Distribution

The rotor surface static pressure distributions at three spanwise locations are shown in Figure 4. No apparent flow separation could be observed from an interrogation of the computed velocity field. The computed static pressures are consistent with those of Tirres [2] computed using a quasi-3D throughflow approach. A comparison of the present results reveals that the inclusion of the clearance flowmodel produces better agreement with the measured data. The biggest discrepancies between computation and measured data can be found in the backface clearance region at the suction surface. Note that most of the blade loading occurs in the radial portion of the rotor where the effects of leakage flows are most pronounced. It can be observed that near the leading edge, the loading is reduced when the clearance model is included. The computations also show a large suction-surface leading edge overspeed. With inclusion of clearance leakage, the suction-surface overspeed is somewhat reduced. This implies that the optimum rotor incidence is affected by the local clearance flow or vice versa. Thus, resetting the nozzle vanes to obtain near optimum incidence may be advantageous in terms of controlling the adverse 
effects of leakage.

\section{INTERNAL FLOW STRUCTURE}

\section{Physical Nature of Rotor Intemal Flow}

There are two features which are predominant in establishing the intemal flow structure of the radial turbine. They are, (1) secondary flow due to the development of the streamwise component of vorticity and (2) the leakage flow through backface and shroud clearances. These two flows are illustrated in Figure 5 for three cross-flow sections of a radial turbine rotor.

Lakshminarayana and Horlock [14] provided an expression for the development of absolute vorticity along a rotor relative streamline. This expression qualitatively shows that for a rotational inlet flow, the development of streamwise vorticity is primarily influenced by streamline curvature and Coriolis acceleration. The direction of flow movement is determined partly by the static pressure field and partly by the centrifugal force field.

In the radial part of the rotor (1-1 of Fig. $5)$, the tangential component of Coriolis acceleration is very large and is in the direction of vorticity due to endwall boundary layers. This generates a streamwise component of vorticity tending to move low momentum fluid from the pressure surface towards the suction surface. Thus, two passage vortices appear due to acceleration of boundary layer fluid on the two endwalls. Since the backface and shroud surfaces are moving relative to the rotor, the fluid in the clearance regions will be dragged opposite to the direction of rotor rotation thereby strengthening the secondary flow due to the passage vortices. Close to the blade ends, backface and shroud leakage flows driven by the pressure difference between suction and pressure surfaces will carry a velocity component roughly perpendicular to the mean camber line as they emerge at the suction side of the blade. These leakage flows will impinge upon the passage vortex secondary flows and may result in a complex interaction. For the case with a substantial backface clearance, the backface leakage flow will roll-up into a vortex tending to displace or possibly stretch the hub passage vortex.

In the radial-to-axial bend (section 2-2), generation of streamwise vorticity is mostly due to meridional streamline curvature. The acceleration caused by the meridional curvature is in the direction of the blade surface boundary layers. This generates a secondary flow tending to transport low momentum fluid from hub to tip near the suction side of the blade. There is also a secondary flow due to streamwise vorticity generation by Coriolis acceleration. At the blade tip; the Coriolis acceleration will have mostly a radial component because of the relative swirl introduced by the blade tuming. This will cause some of the fluid being dragged by the relative motion between the shroud and blade to be transported spanwise inward and then to eventually end up near the suction surface. At the same time, the rolling-up of the shroud leakage vortex will push the low momentum fluid away from the suction surface.

In the exducer (section 3-3), streamwise vorticity is generated by the radial component of Coriolis acceleration which is in the direction of vorticity due to blade surface boundary layers. This results in the transport of low momentum fluid from hub to shroud near the suction surface. The acceleration due to blade curvature tends to promote flow movement from the pressure to the suction surface. It is also expected that the low momentum fluid in the wake will be centrifuged outward due to an imbalance of radial forces on the slow moving fluid particles. This wake flow will be carried into the mainstream by the shroud leakage. At the same time, the dragging due to relative motion between shroud and blade tip will contribute to the spanwise inward movement of flow along the pressure surface.

\section{Computational Evidence}

The internal flow development in the rotor is illustrated in Figure 6 in terms of entropy contours at various cross-flow planes along the meridional length of the rotor. This figure corresponds to the backface and shroud clearance flow-model. The plots indicate the locations of the high entropy cores due to leakage and the viscous dissipation in the wake. Note also the circumferential and spanwise 
redistribution of these high entropy regions.

At 10 and 20 percent $\left(x / c_{m}=0.10\right.$ and $0.20)$ of meridional chord, high entropy regions due to the backface and shroud leakage flows are evident. The circumferential enlargement of the high entropy core in the backface-leakage region can be observed when proceeding downstream from $x / c_{m}=0.10$ to $\times / c_{m}=0.30$ along the rotor. Note that between $x / c_{m}=0.20$ and $x / c_{m}$ $=0.30$ this high entropy core starts to migrate spanwise outward. These observations are consistent with the previous discussion concerning the nature of the flow in the radial part of the rotor (1-1 of Fig. 5).

Figure 6 also shows that at $x / c_{m}=0.50$, corresponding to the radial-to-axial bend of the rotor, the high entropy core due to the shroud leakage flow is magnified. Again this is consistent with Figure 5. The roll-up of the shroud leakage vortex and its interaction with the spanwise outward migration of low momentum fluid along the suction surface is responsible for the entropy distribution exhibited at $x / c_{m}=0.50$ in Figure 6 . Proceeding from $x / c_{m}=0.70$ to the trailing edge $\left(x / c_{m}=1.0\right)$, the development of the wake and the accumulation of high entropy fluid near the shroud can be seen.

Figure 7 shows the " secondary " velocities driving the flow redistribution. These secondary velocities were obtained by projecting the velocity vectors onto the cross-flow plane. Observe the backface leakage vortex at $x / c_{m}=0.10$ and the interaction of the shroud leakage flow with the spanwise migration of lowmomentum fluid at $x / c_{m}=0.5$. Further indications of the spanwise migration of the flow near the rotor suction surface are given in Figure 8 . This figure also compares the zero-clearance model with that having backface and shroud leakage. Note that the clearance flow significantly alters the flow pattern in the radial portion of the rotor near the suction surface. The spanwise migration of fluid appears to be reduced or delayed until the radial-to-axial bend for the case with backface leakage. Also, very near the shroud, the surface flow is directed toward the hub due to the wall dragging. These observation are consistent with experimental flow visualizations of Huntsman et al. [15].
The rotor trailing edge entropy and relative kinetic energy contours are presented in Figure 9. A comparison of the zero clearance and backface and shroud clearance models can be made from this figure. It can be seen that the entropy is highest in the suction surface side of the wake above the 70 percent span region. There exists a high entropy core close to the shroud extending pitchwise. The pitchwise extent of this region is larger with the clearance flowmodel as was observed by Heidmann [5] and Zangeneh-Kazemi et al. [3].

Also of interest in Figure 9, are the relative kinetic energy contours. A high kinetic energy region can be seen near the suction surface due to flow acceleration in the passage. Also evident is a high kinetic energy region on the pressure surface near the shroud. This is due to the movement of high relative kinetic energy fluid from the stationary shroud by relative motion between the shroud and blade tip. However there exists, in addition to the wake, a region of low kinetic energy sandwiched between suction and pressure surfaces in the upper 70 percent span region as experimentally observed by Borges [16]. This low kinetic energy zone also corresponds to a region of high entropy and absolute flow angle. The mechanisms responsible for the presence of this low kinetic energy zone are created by the interaction of secondary flow due to streamwise vorticity with the dragging of the fluid elements near the shroud. These mechanisms are enhanced by the transport of low momentum fluid into the mainstream through the action of the shroud leakage flow. Thus, the flow is more nonuniform at the rotor trailing edge with clearance leakage flows.

The flow transition from the rotor trailing edge to the rotor exit is illustrated in Figure 10 by way of entropy contours at the rotor exit plane. It can be observed that even though the circumferentially averaged spanwise profiles are similar for both the clearance and zero-clearance flow models, the circumferential non-uniformities are much more pronounced with the inclusion of the backface and shroud clearance flow model. This non-uniformity is reflective of the flow blockage downstream of the rotor trailing edge and may also account for the difference in losses between the clearance and zero-clearance flow 
models.

\section{CONCLUSIONS}

The flow through a radial turbine rotor was analyzed using a three-dimensional NavierStokes code. An agreeable comparison with the available test data was obtained when a simple backface and shroud clearance flow-model was included. Aerodynamic teatures of the internal flow in the rotor under the influence of backface and shroud leakage flows were described and explained. The computations corroborated the theoretical notions of secondary flows generated from the creation of streamwise vorticity and their interactions with the leakage flows.

An interesting result of this investigation is the existence of a localized zone of low relative kinetic energy sandwiched between suction and pressure surfaces near the shroud at the rotor trailing edge. It is felt that reduction of this zone by regulating the clearance and secondary flows may lead to better recovery downstream of the rotor thereby improving the overall performance.

\section{REFERENCES}

1. Snyder, P. H. and Roelke, R. J., "The Design of an Air-Cooled Metalic High Temperature Radial Turbine," AlAA Paper 88-2872, 1988.

2. Tirres, L., " A Comparison of the Analytical and Experimental Performance of the Solid Version of a Cooled Radial Rotor," AIAA Paper 80-0300, 1980.

3. Zangeneh-Kazemi, M., Dawes, W. N., and Hawthorne, W. R., " Three Dimensional Flow in Radial Turbines," ASME Paper No. 88-GT-103.

4. Heidmann, J. D. and Beach, T. A., " An Analysis of the Viscous Flow Through a Compact Radial. Turbine by the Average Passage Approach," NASA TM No. 102471, June, 1990 and ASME Paper No. 90-GT-64.

5. Heidmann, J. D., " A Three-Dimensional Navier-Stokes Stage Analysis of the Flow Through a Compact Radial Turbine," NASA TM
No. 104420, June, 1991.

6. Adamczyk, J. J., " Model Equations for Simulating Flows in Multistage Turbomachinery," NASA TM No. 86869, November, 1984 and ASME Paper No. 85-GT-226.

7. Chima, R. V., "Viscous Three-Dimensional Calculations of Transonic Fan Performance," in CFD Techniques for Propulsion Applications, AGARD CP-510, Feb. 1992, pp 21-1 to 21-19.

8. Baldwin, B. S. and Lomax, H., " Thin-Layer Approximation and Algebraic Model for Separated Turbulent Flows," AIAA Paper 78257, January, 1978.

9. Chima, R. V. and Yokota, J. W., " Numerical Analysis of Three-Dimensional Viscous internal Flows," AlAA J., Vol. 28, No. 5, May 1990, pp. 798-806.

10. Boyle, R. J., " Navier-Stokes Analysis of Turbine Blade Heat Transfer," J. of Turbomachinery, Vol. 113, July 1991.

11. Rains, D. A., " Tip Clearance Flows in Axial Flow Compressors and Pumps," California Institute of Technology Report No. 5, June, 1954.

12. Kirtley, K. R., Beach, T. A., and Adamczyk, J. J., " Numerical Analysis of Secondary Flow in a Two-Stage Turbine," AIAA Paper 90-2356.

13. Meitner, P. L. and Glassman, A. J., " Computer Code for Off-Design Performance Analysis of Radial-Inflow Turbines with Rotor Blade Sweep," NASA TP 2199, August 1983.

14. Lakshminarayana, B. and Horlock, J. H., " Generalized Expressions for Secondary Vorticity Using Intrinsic Co-Ordinates," J. Fluid Mech, Vol. 59, pp 97-115.

15. Huntsman, I., Hodson, H. P., and Hill,S. H., " The Design and Testing of a Radial Flow Turbine for Aerodynamic Research," ASME Paper No. 91-GT-220, June 1991.

16. Borges, J. F., " Three-Dimensional Inverse Design of Turbomachinery," Ph.D. Thesis, Cambridge University Engineering Department. 


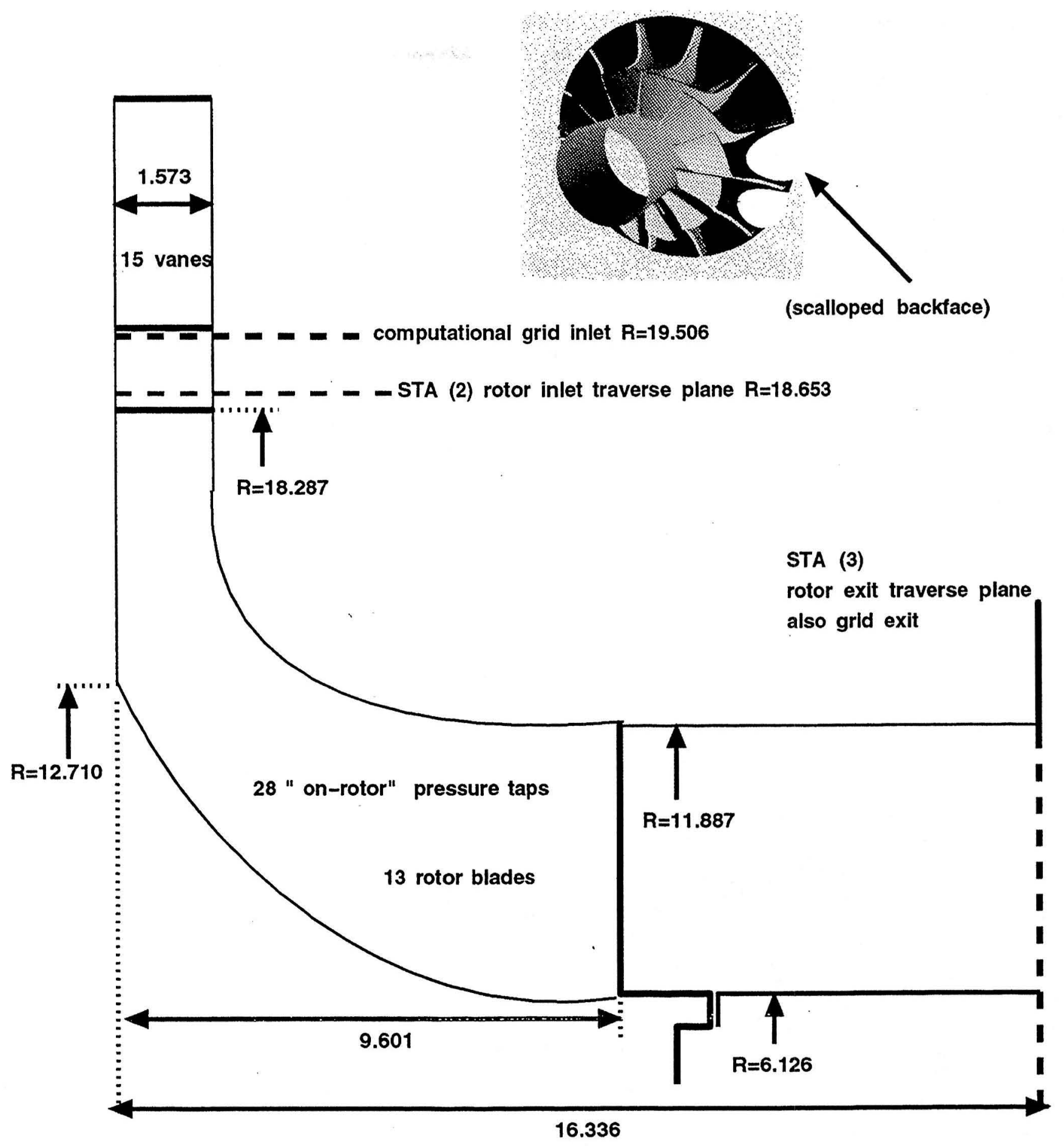

Figure 1. Meridional projection of radial turbine rotor indicating primary flowpath dimensions, locations of the rotor inlet and exit traverse planes, and computational grid boundaries. Dimensions are in centimeters. 


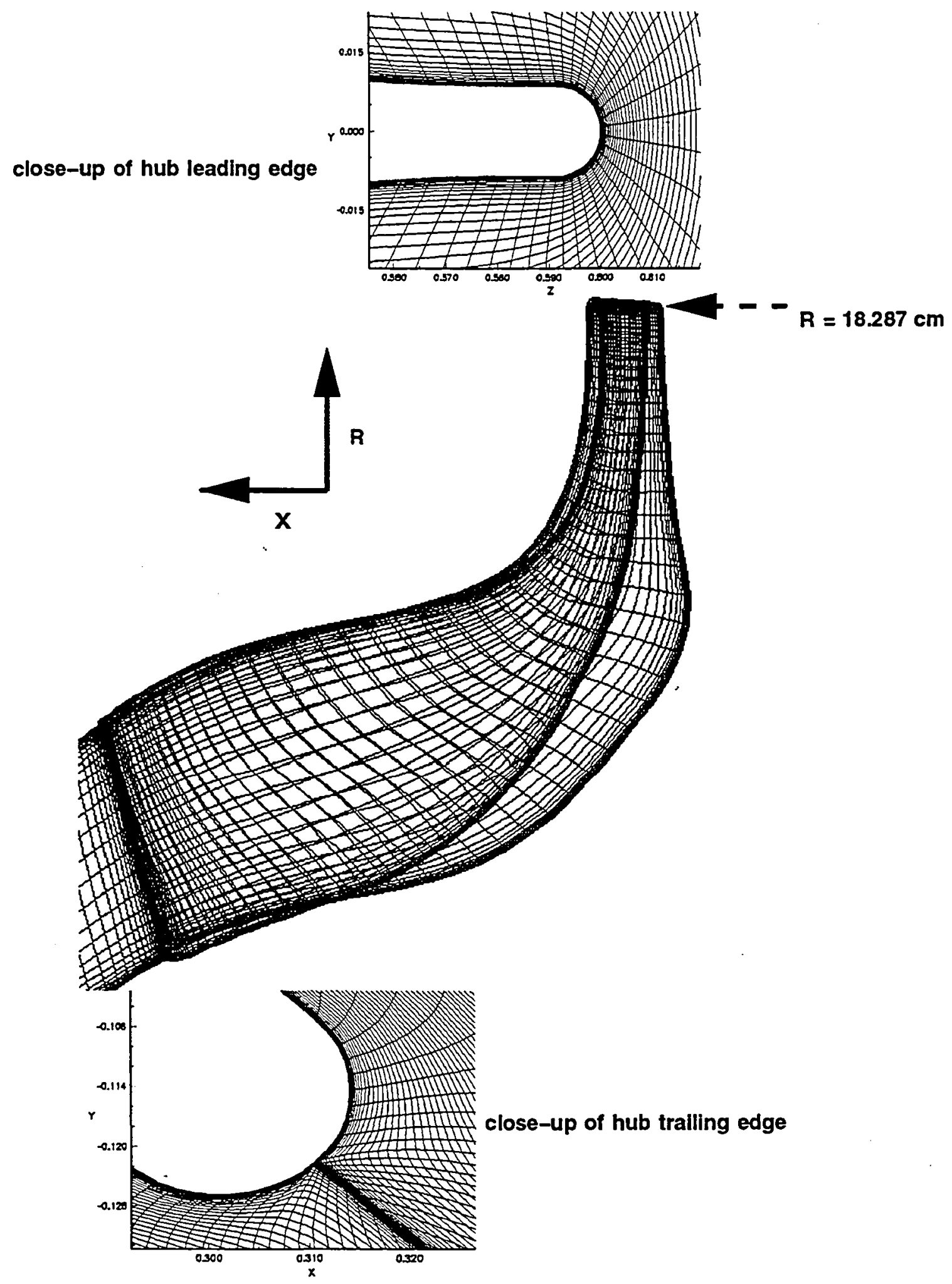

Figure 2. Computational mesh consisting of 50 quasi-streamlines, 200 quasi-orthogonals, and 50 blade-to-blade stations. 


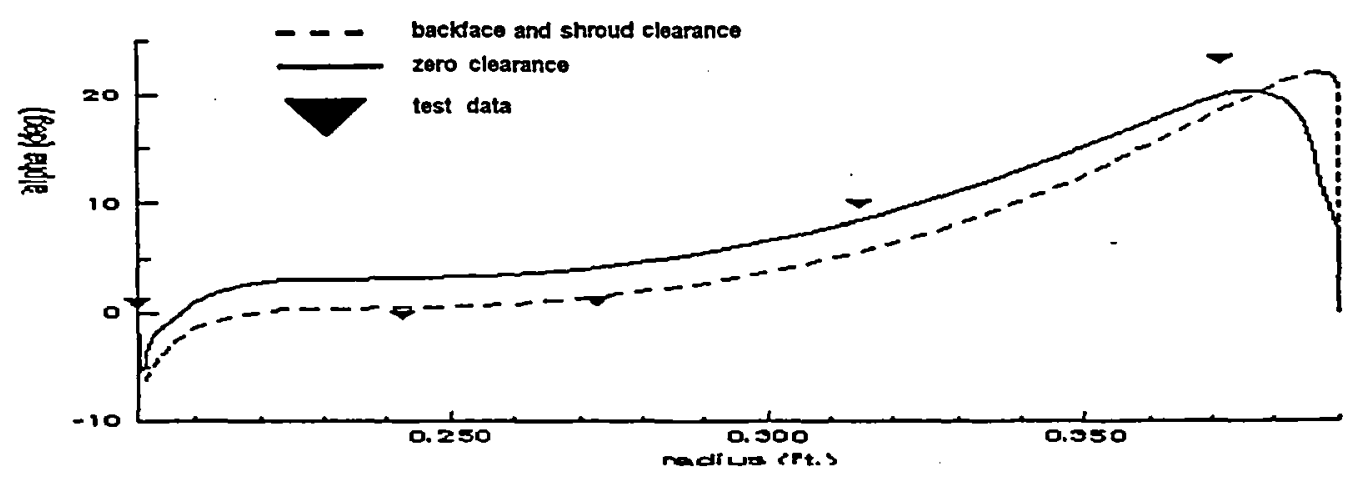

(a) rotor exit swirl angle

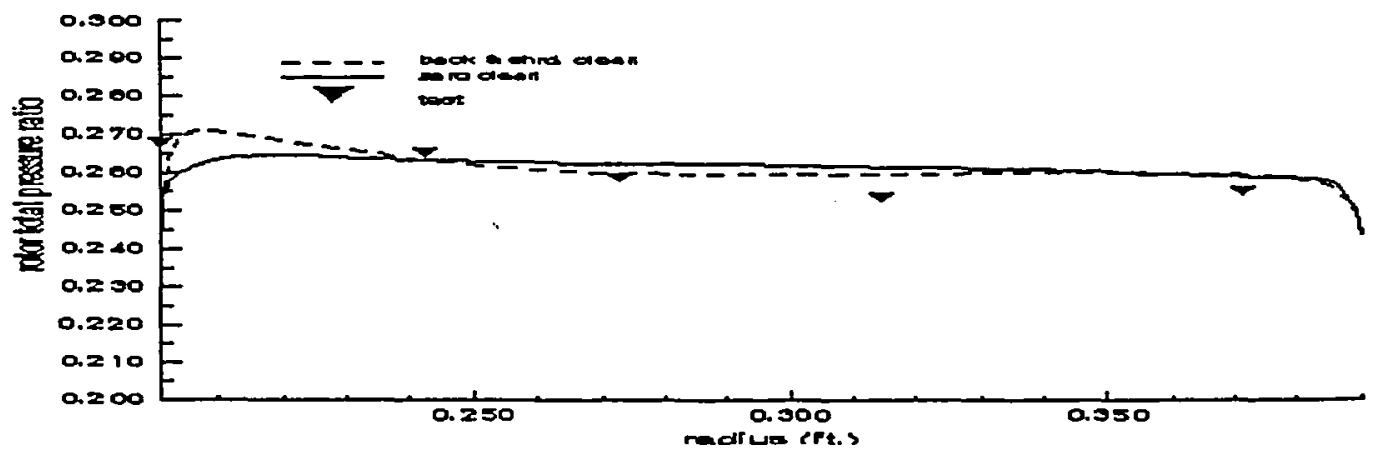

(b) rotor normalized total pressure

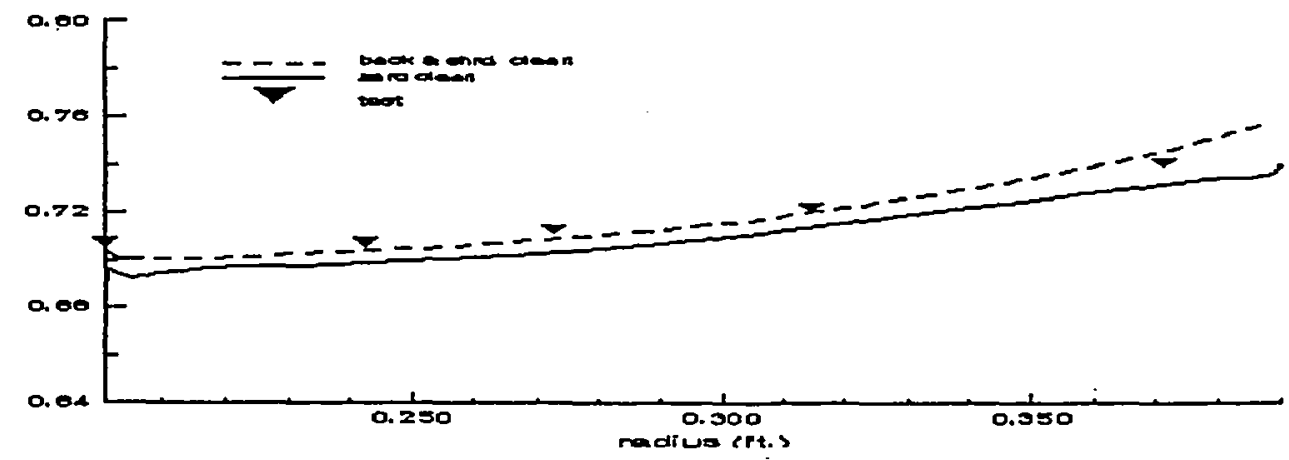

(c) rotor normalized total temperature

Figure 3. Rotor spanwise exit profiles; (-) zero clearance, (- - -) backface and shroud clearance, (symbols) test data. 


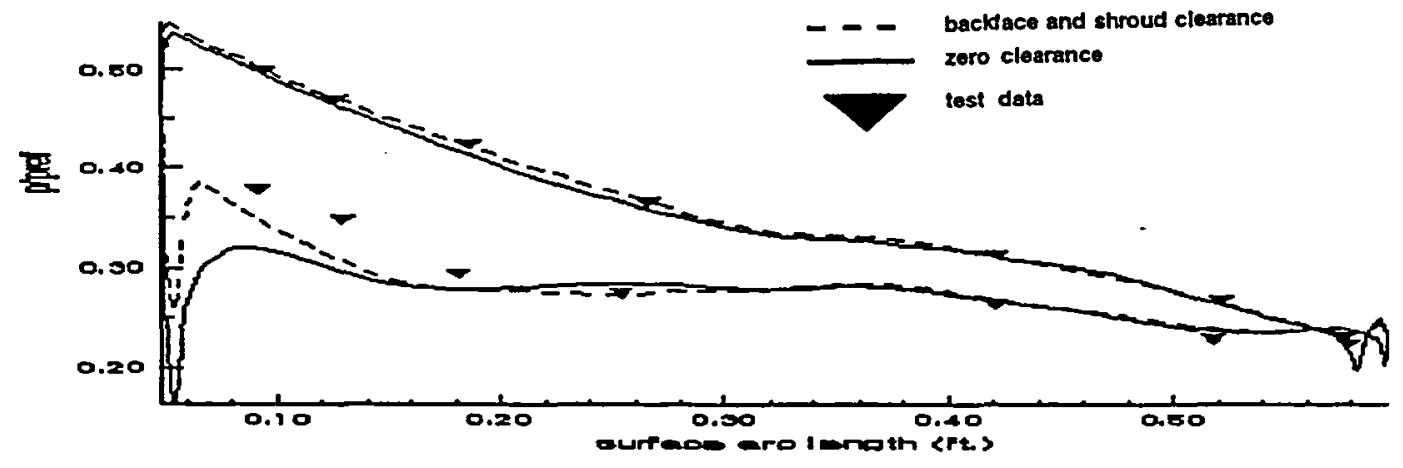

(a) $22 \%$ span (near hub) [backface ends at $.183 \mathrm{ft}$ of arc length]

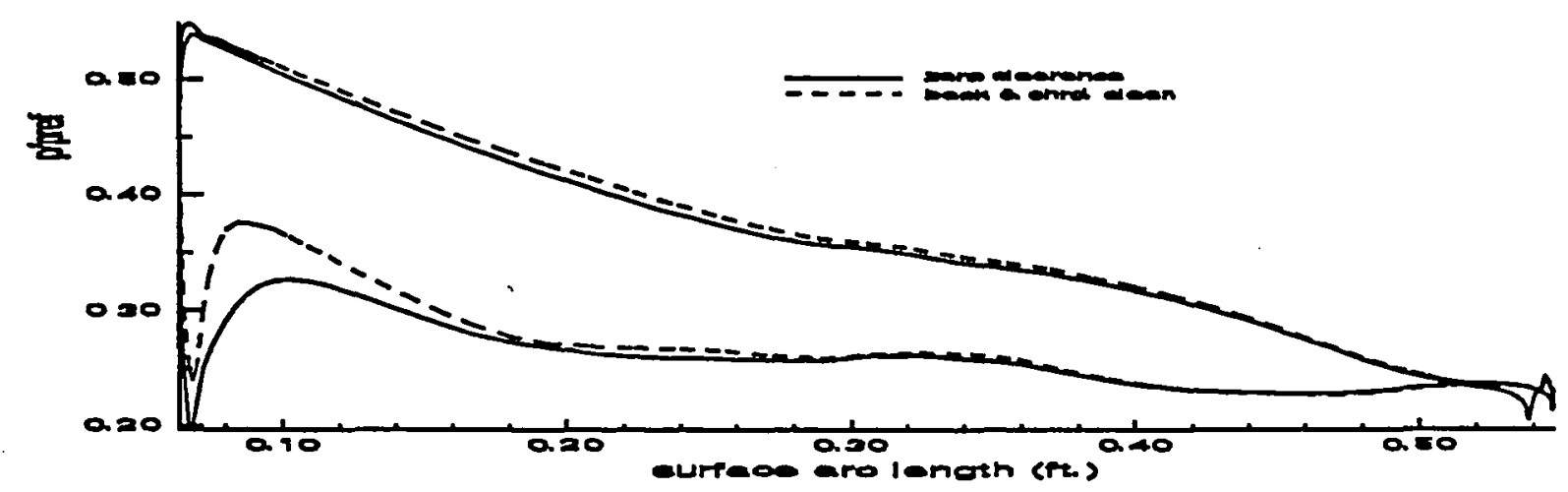

(b) $54.5 \%$ span

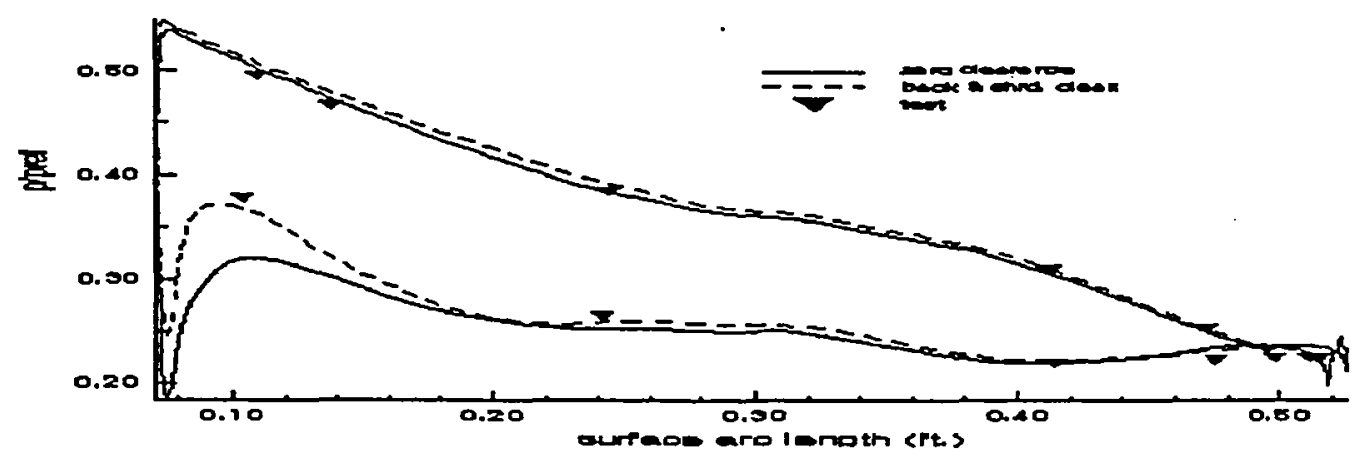

(c) $71 \%$ span (near shroud)

Figure 4. Rotor static pressure distribution normalized by mass-averaged inlet value; $(-)$ zero clearance, (- - -) backface and shroud clearance, (symbols) test data. 


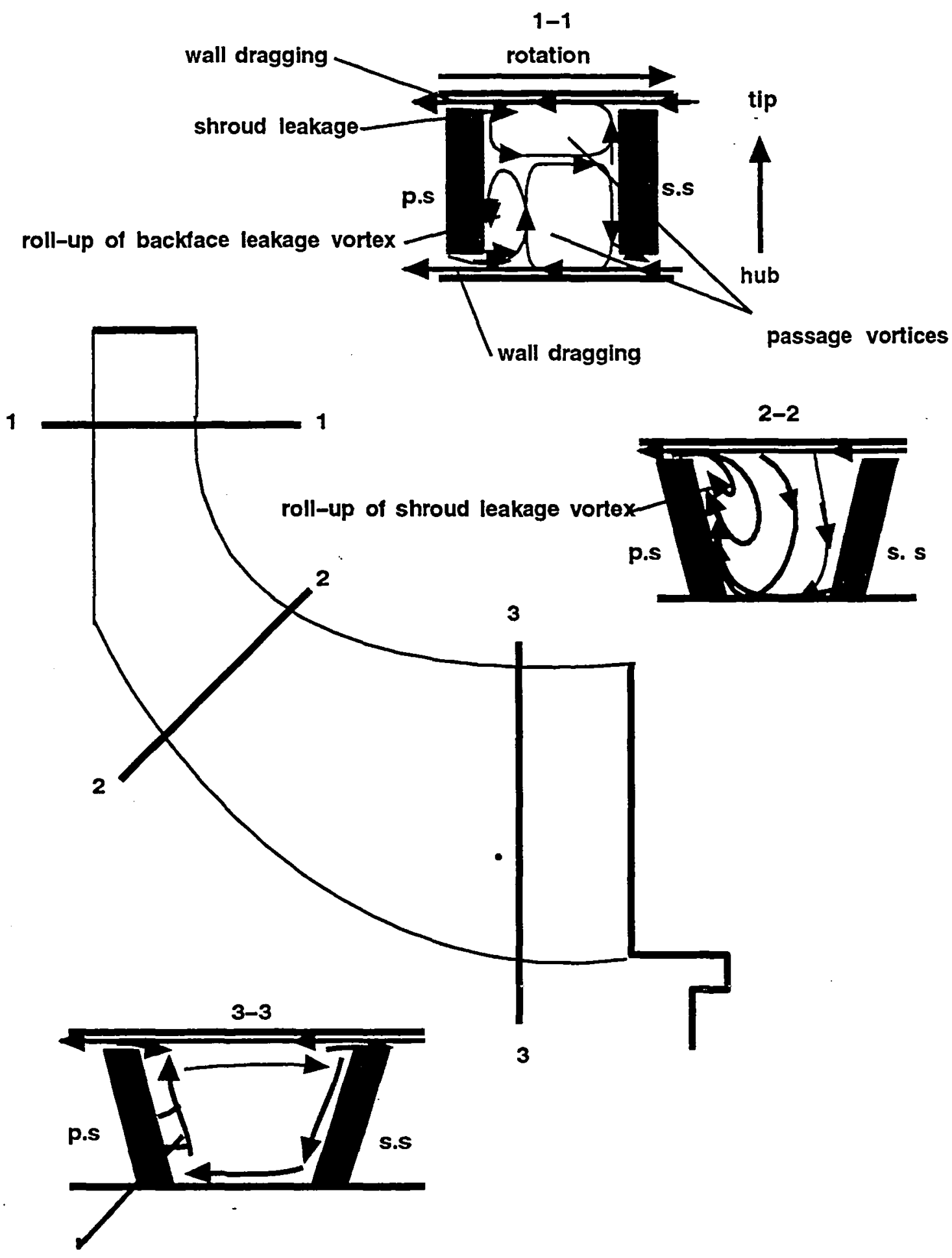

spanwise migration of wake fluld

Figure 5. Schematic representation of fluid movement on three quasi-normal surfaces of a radial turbine. 

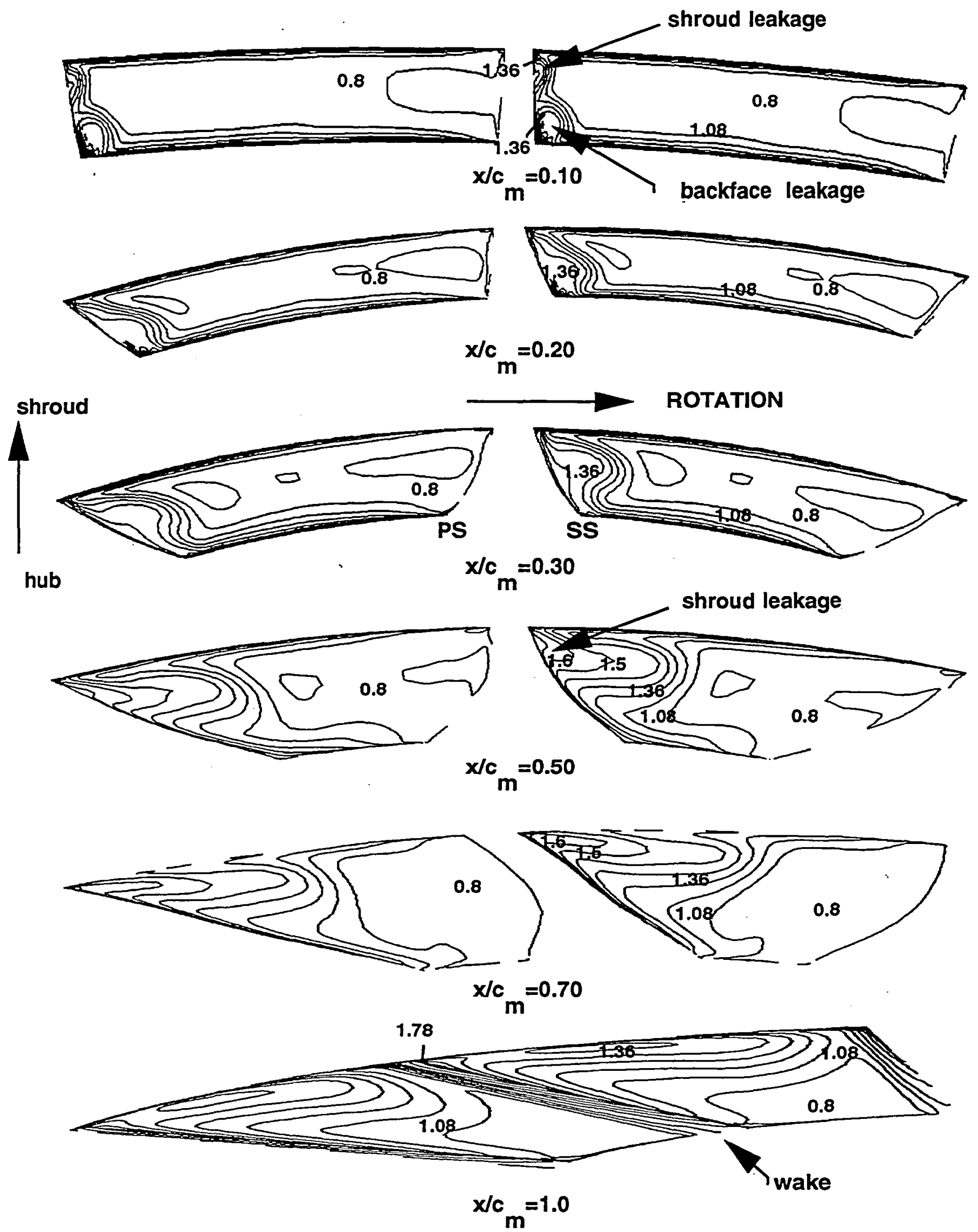

Figure 6. Entropy contours at various cross-flow planes in the rotor illustrating the internal flow development. $x / c_{m}$ denotes percent of rotor meridional chord at mid-span. 

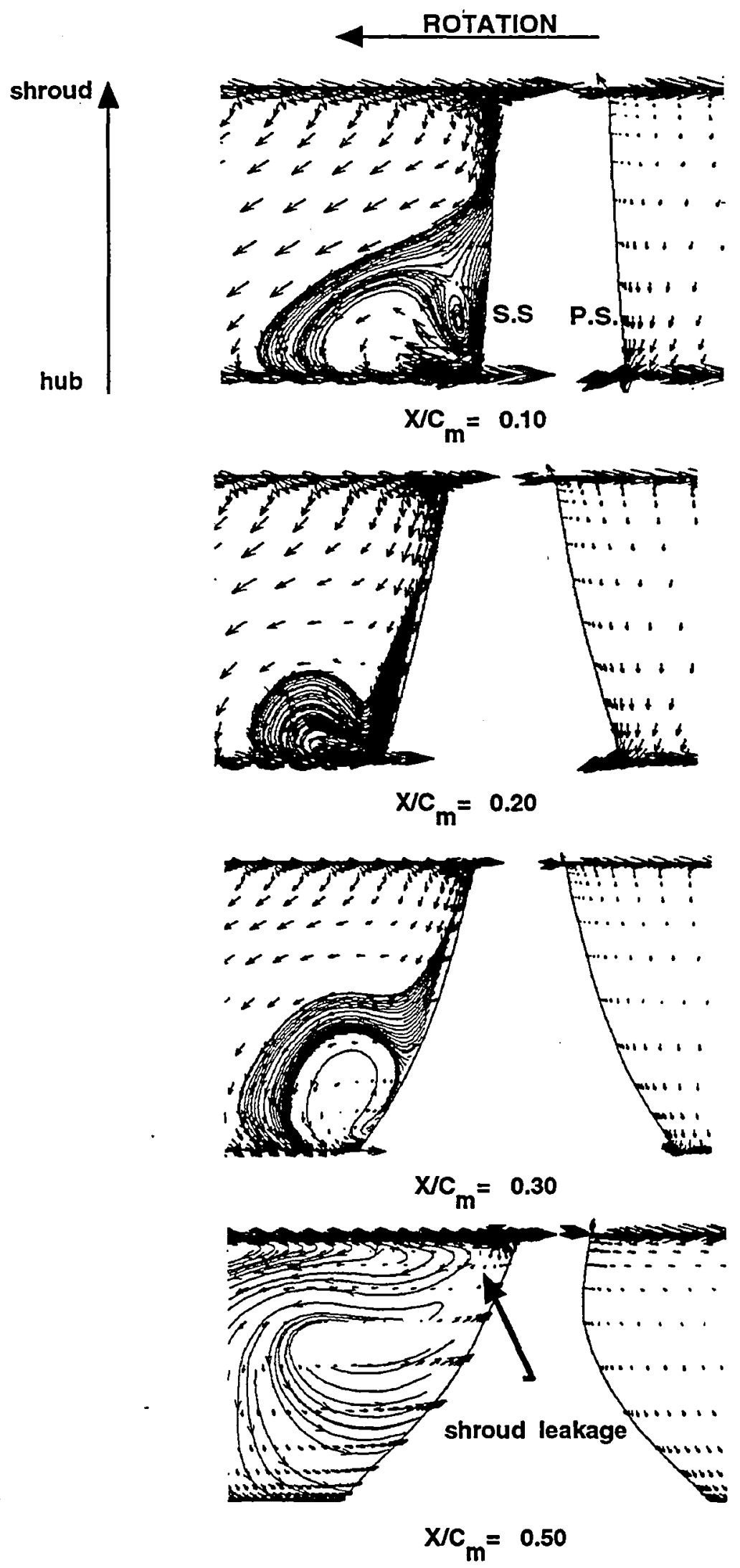

Figure 7. Flow development in the rotor: projected velocity vectors and streamlines on quasi-normal planes. 


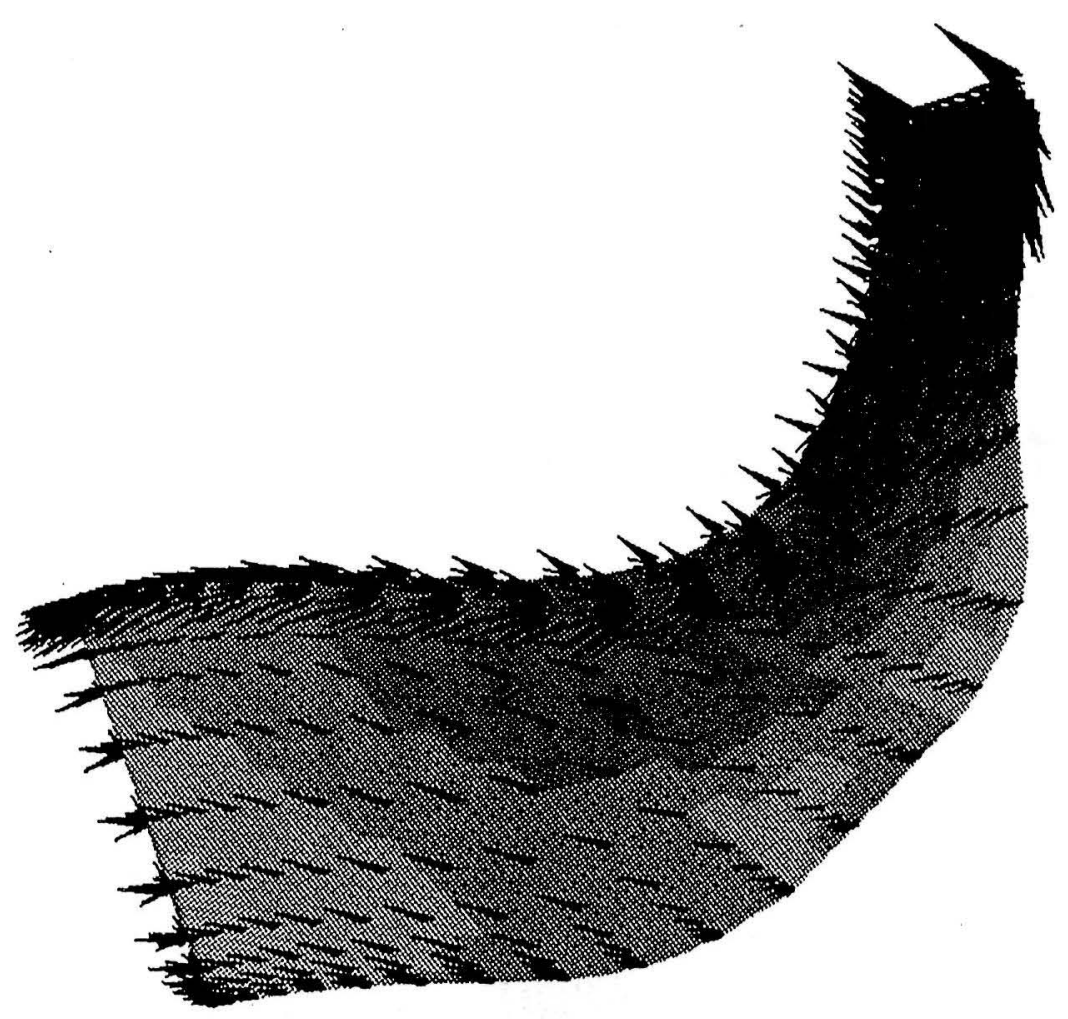

(a) zero clearance

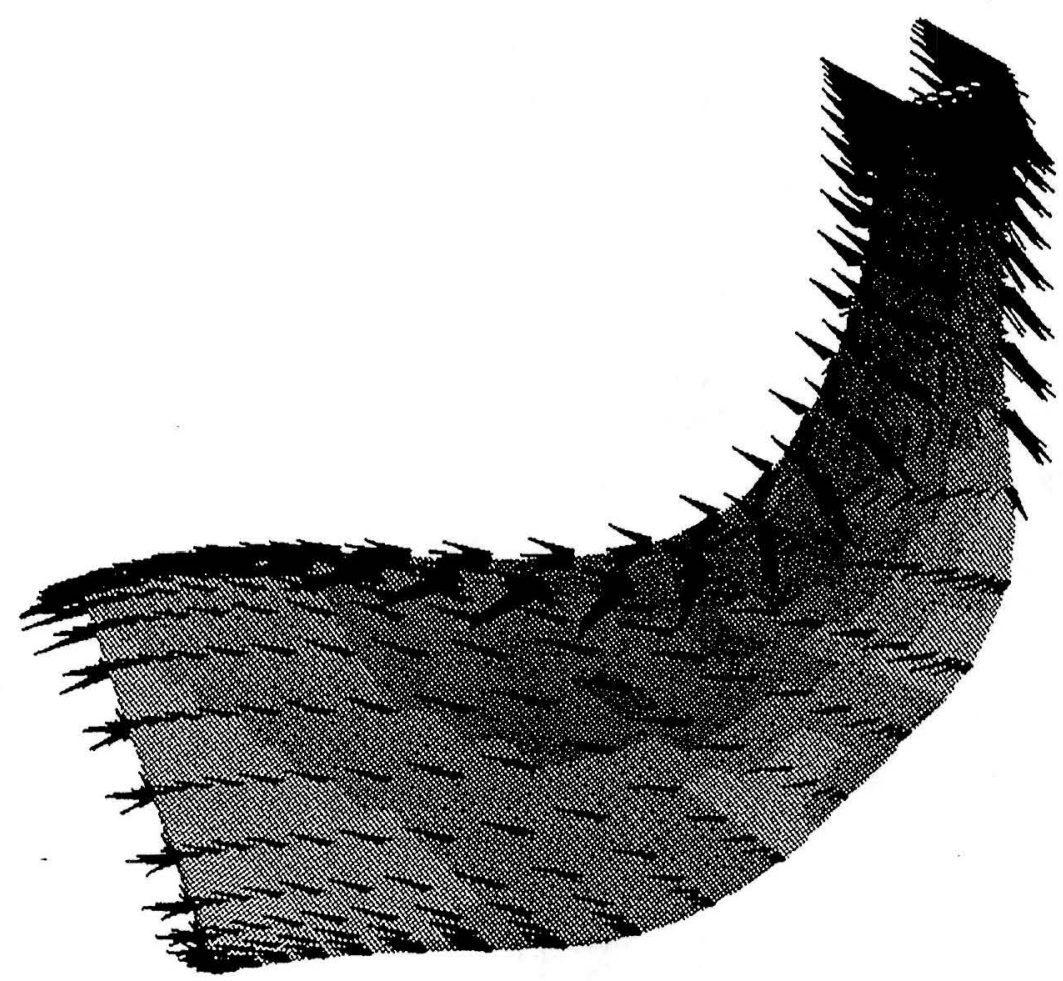

(b) backface and shroud clearance

Figure 8 . Relative velocity vectors near the suction surface illustrating spanwise migration of fluid elements. 

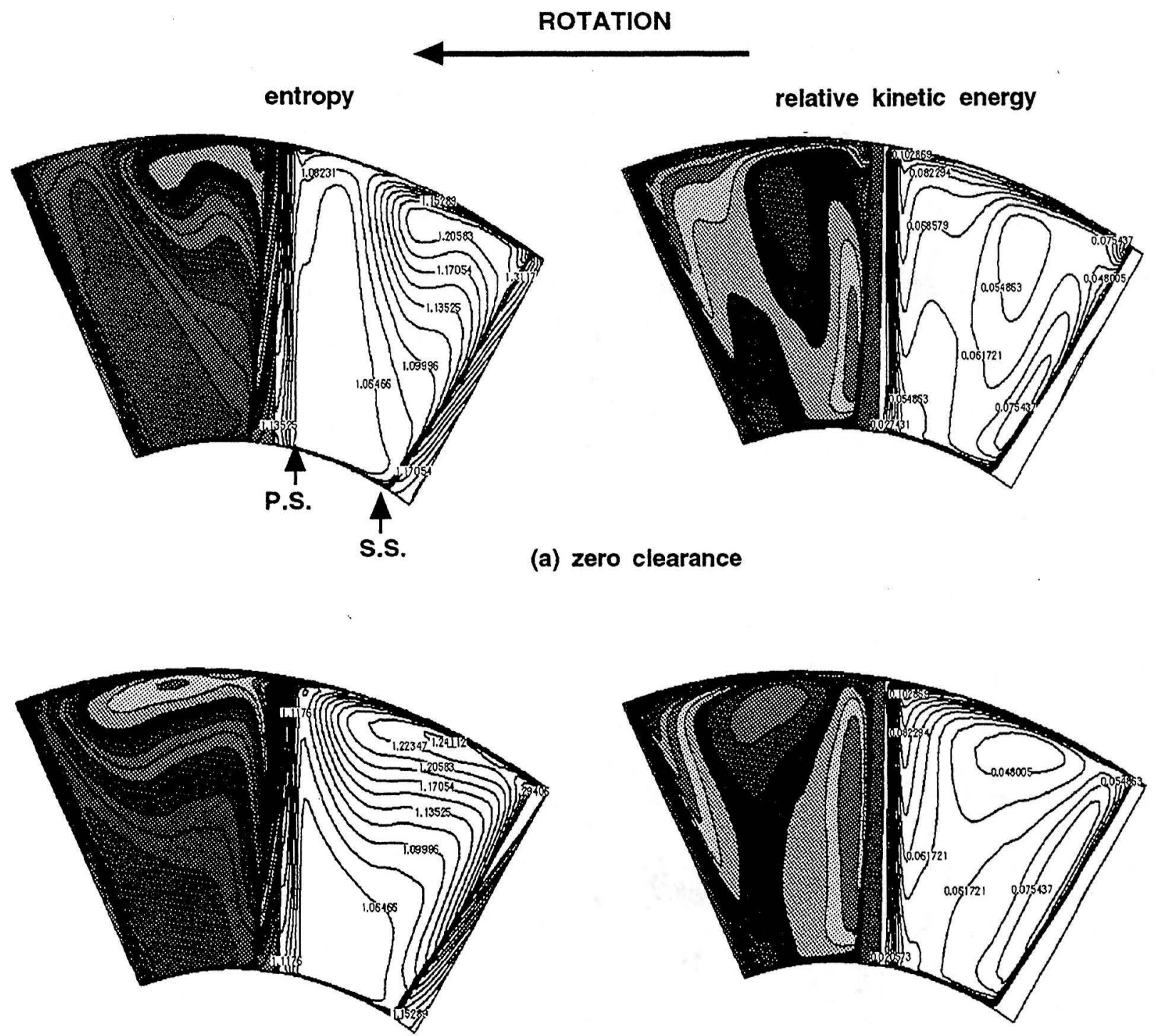

(b) backface and shroud clearance

Figure 9. Rotor trailing edge entropy and kinetic energy contours illustrating the effect of leakage flows. 


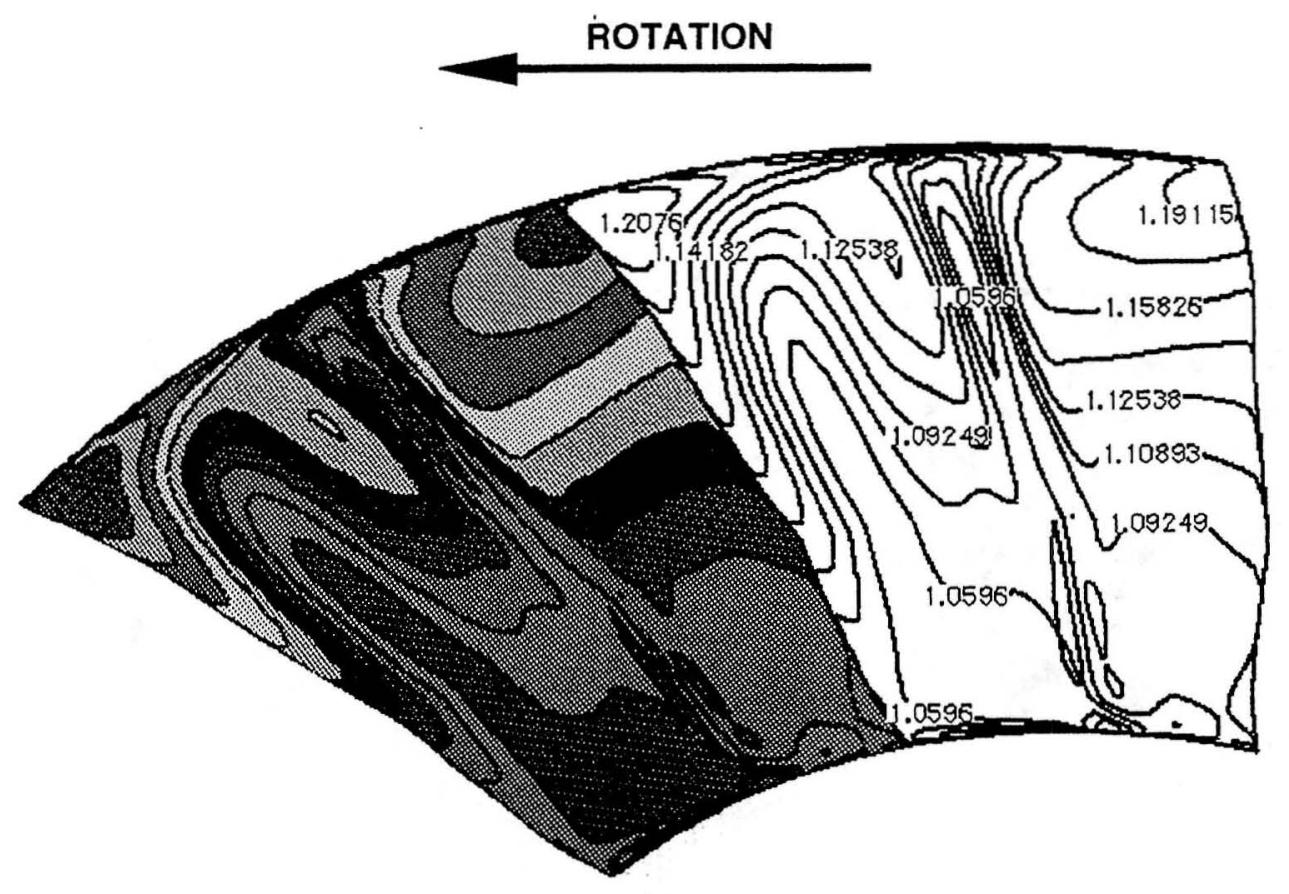

(a) zero clearance

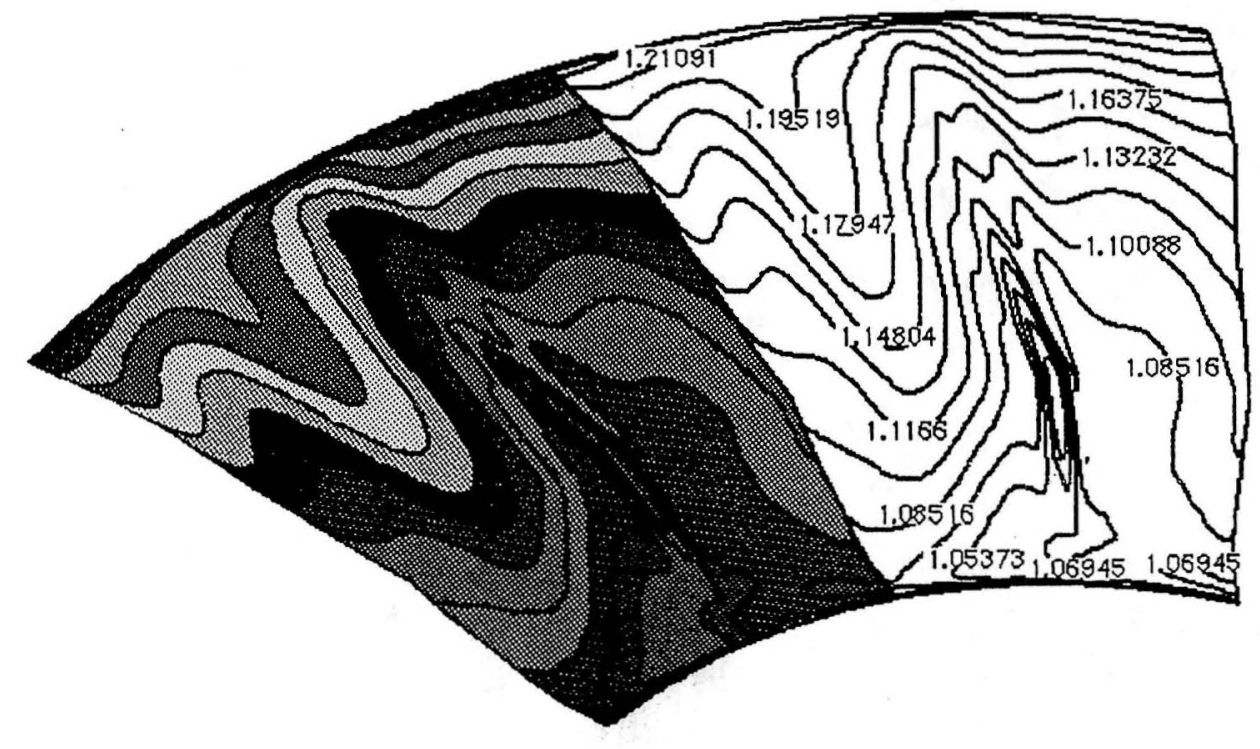

(b) backface and shroud clearance

Figure 10. Rotor exit entropy contours (STA. 3) . 
Public reporting burden for this collection of information is estimated to average 1 hour per response, including the time for reviewing instructions, searching existing data sources, gathering and maintaining the data needed, and completing and reviewing the collection of information. Send comments segarding this burden estimate or any other aspect of this collection of information, including suggestions for reducing this burden, to Washington Headquarters Services, Directorate for Information Operations and Reports, 1215 Jefter
Davis Highway, Suite 1204, Artington, VA 22202-4302, and to the Office of Management and Budget, Paperwork Reduction Project (0704-0188), Washington, DC 20503.

\begin{tabular}{|c|c|c|}
\hline 1. AGENCY USE ONLY (Leave blank) & $\begin{array}{r}\text { 2. REPORT DATE } \\
\text { June } 1993\end{array}$ & $\begin{array}{l}\text { 3. AEPORT TYPE AND DATES COVERED } \\
\text { Final Contractor Report }\end{array}$ \\
\hline \multirow{2}{*}{\multicolumn{2}{|c|}{$\begin{array}{l}\text { 4. TITLE AND SUBTITLE } \\
\text { Navier-Stokes Analysis of Radial Turbine Rotor Performance }\end{array}$}} & \multirow{3}{*}{$\begin{array}{l}\text { 5. FUNDING NUMBERS } \\
\text { WU-505-62-10 } \\
\text { NCC-208 }\end{array}$} \\
\hline & & \\
\hline \multicolumn{2}{|l|}{$\begin{array}{l}\text { 6. AUTHOR(S) } \\
\text { L.M. Larosiliere }\end{array}$} & \\
\hline \multicolumn{2}{|c|}{$\begin{array}{l}\text { 7. PERFORMING ORGANIZATION NAME(S) AND ADDRESS(ES) } \\
\text { Ohio Aerospace Institute } \\
22800 \text { Cedar Point Road } \\
\text { Brook Park, Ohio } 44142\end{array}$} & $\begin{array}{l}\text { 8. PERFORMING ORGANIZATION } \\
\text { REPORT NUMBER } \\
\text { E-7937 }\end{array}$ \\
\hline \multicolumn{2}{|c|}{$\begin{array}{l}\text { 9. SPONSORING/MONITORING AGENCY NAME(S) AND ADDRESS(ES) } \\
\text { National Aeronautics and Space Administration } \\
\text { Lewis Research Center } \\
\text { Cleveland, Ohio } 44135-3191\end{array}$} & $\begin{array}{l}\text { 10. SPONSORING/MONITORING } \\
\text { AGENCY REPORT NUMBER } \\
\text { NASA CR-191153 } \\
\text { AJAA-93-2555 }\end{array}$ \\
\hline
\end{tabular}

\section{SUPPLEMENTARY NOTES}

Prepared for the 29th Joint Propulsion Conference and Exhibit cosponsored by the AIAA, SAE, ASME, and ASEE, Monterey, California, June 28-30, 1993. Project Manager, Lawrence J. Bober, (216) 433-3944.

\begin{tabular}{|l|l|}
\hline 12a. DISTRIBUTION/AVAlLABILTY STATEMENT & 12b. DISTRIBUTION CODE \\
Unclassified - Unlimited & \\
Subject Category 07 & \\
\end{tabular}

\section{ABSTRACT (Maximum 200 words)}

An analysis of flow through a radial turbine rotor using the three-dimensional, thin-layer Navier-Stokes code RVC3D is described. The rotor is a solid version of an air-cooled metallic radial turbine having thick trailing edges, shroud clearance, and scalloped-backface clearance. Results are presented at the nominal operating condition using both a zero-clearance model and a model simulating the effects of the shroud and scalloped-backface clearance flows. A comparison with the available test data is made and details of the internal flow physics are discussed, allowing a better understanding of the complex flow distribution within the rotor.

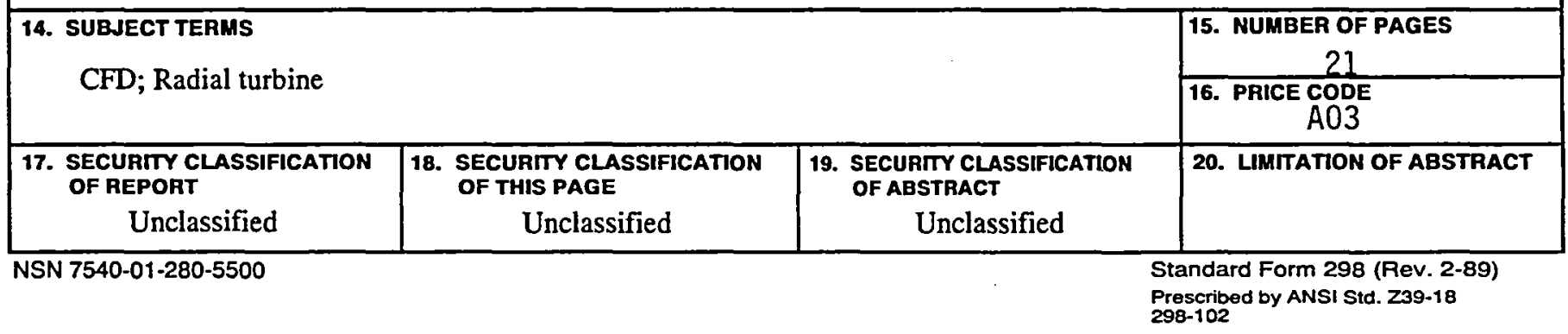


National Aeronautics and Space Administration

Lewis Research Center

Cleveland, Ohio 44135

Oritedal Buelnese

Penety for Prtvete Use 8900
FOURTH CLASS MAIL

|||||

ADDRESS CORRECTION REQUESTED 